\title{
THE INTEGRATED SURVEY OF NARROW SPACES AND UNDERGROUND ARCHITECTURE: THE CASE STUDY OF CAMPANA CAVES BAS-RELIEFS
}

\author{
P. Clini ${ }^{1}$, R. Nespeca ${ }^{1}$, R. Angeloni ${ }^{1}$, R. Mammoli ${ }^{1}$ \\ ${ }^{1}$ DICEA, Dept. of Civil and Building Engineering and Architecture, Polytechnic University of Marche, Ancona, Italy \\ (p.clini, r.nespeca)@univpm.it, (r.angeloni,r.mammoli)@pm.univpm.it
}

\section{Commission II}

KEY WORDS: narrow spaces, underground architecture, terrestrial laser scanning, photogrammetry, bas-relief, immersive virtual reality

\begin{abstract}
:
Italian Cultural Heritage is rich in fascinating Underground Heritage (UH) to be protected and preserved because of its fragility and historical importance. An accurate and high-resolution 3D model is essential to reach an appropriate level of knowledge to safeguard caves but there are several obstacles to face. Underground data acquisition and following elaborations are problematic due to environmental conditions such as lack of homogeneous light sources, highly absorbing and unstable surfaces, narrow spaces and complex geometry. For these reasons, the integration of different techniques is mandatory to achieve a valid final product that could be an important basis for consolidation, preservation and valorization of the UH. In this paper, an integrated survey method is tested for a realistic digital reconstruction of hypogeal spaces. In addition to outputs for experts of conservation, the creation of multimedia products for a wider audience of non-professionals users is investigated as a way to preserve UH from decay. Thanks to VR, visitors virtually walk through the underground galleries observing and interacting, making accessible also fragile environments with forbidden access due to preservation policies
\end{abstract}

\section{INTRODUCTION}

Hypogeal environments are widely spread throughout Italy representing a considerable part of national Cultural Heritage. It is not just narrow tunnels and dark passages, but decorated galleries telling the history of the communities who lived these places. For this reason, it is important to safeguard Underground Heritage (UH) from degradation through an in-depth study and the most complete as possible knowledge of them.

The case study examined in this work is a typical example of $\mathrm{UH}$; the Palazzo Campana Caves are in fact part of a larger network of underground spaces that can be accessed by going down below the noble buildings of which they are part.

This paper presents the results of the integrated survey of these galleries realized using Terrestrial Laser Scanning (TLS), Digital Photogrammetry (DP) and Global Navigation Satellite System (GNSS). It also allows a comparison between the results in the application of these different techniques to narrow and dark spaces demonstrating how fundamental the integration is to acquire quickly and efficiently comprehensive data under limit light and space conditions.

The case study was accurately and completely documented thanks to the use of different methods and tools. High-resolution images and the reflectance values got from TLS acquisitions show in detail that the sandstone of the decorative pattern is strongly disrupted and affected by the settlement of bacterial or fungal colonies; exfoliation of the stone and loss of some superficial layers are also evident from observation of the point cloud.

The activities done for this work mainly concerned acquisition and data processing but also provided for the creation of an optimized model for Immersive Virtual Reality (IVR). The workflow planned is composed of five main steps (Figure 1). The first was related to the survey of geometric data through TLS and its subsequent georeferentiation using GNNS methodology. The second phase concerned the acquisition of colorimetric data necessary to map the point clouds through photogrammetric techniques. The third step involved data processing and modelling, whereas the fourth was data integration. The last phase provided for the creation of outputs, a virtual tour and an IVR application, for a virtual visit experience promoting in this way the preservation of such a fragile site.

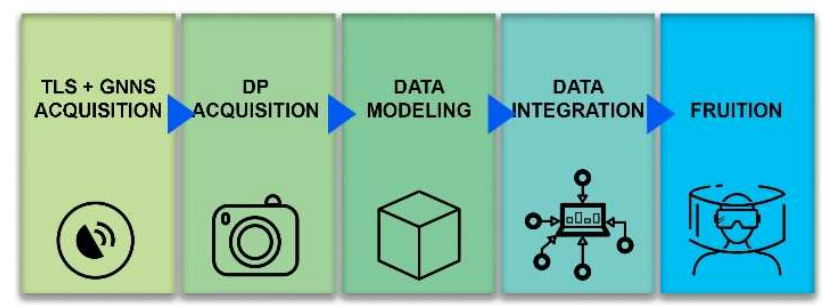

Figure 1: Workflow. 1) acquisition through use of TLS and GNNS methods, 2) digital photogrammetry acquisition, 3) data elaboration and modelling, 4) data integration and 5) fruition with VR implementation.

In particular, this work aimed to stress the potential of an integrated survey to overcome difficulties in the documentation of UH. The need for an accurate documentation of caves current state clearly emerged in the planning of an intervention to contain the threat of degradation hanging over this precious heritage site becoming also a chance to define a less invasive way of fruition. Therefore, this paper tries to test and validate a method for a highresolution photorealistic reconstruction of hypogeal spaces to be virtually navigate by both conservation expert and non-expert.

\section{RELATED WORKS}

The integration of different survey techniques is mandatory to achieve a valid final product that could be an important basis for consolidation, preservation and valorisation of the $\mathrm{UH}$ as in (Murtiyoso et al., 2017) (Mandelli et al., 2017). Today the combination of TLS, DP and GNSS (Liang et al., 2018) is the most effective one for the acquisition and elaboration of high precision point clouds. Furthermore the integration of these methods makes it possible to obtain both accurate and photo- 
realistic 3D models as in (Lerma et al., 2010). Concerning in particular underground data acquisition, it is problematic due to environmental conditions such as lack of homogeneous light sources, highly absorbing and unstable surfaces, narrow spaces and complex geometry. In this regard it is necessary to obtain a high density point cloud to properly represent information related to irregular spaces as in (Rodríguez-Gonzálvez et al., 2015).

(Cardaci et al., 2016) shows an example of underground funerary complex afflicted by the same problems such as hard accessibility, poor visibility, small recognition of their historical and architectural value. This requires a serious reflection on the challenges and requirements needed to ensure both preservation and revitalization of such a heritage.

For these reasons, TLS devices are often used in challenging environments like tunnels, galleries and hypogeal spaces. Due to their technical characteristics, they are useful to create highresolution 3D maps of underground areas such as natural caves, for geomorphological investigations, and to carry out measurements on hypogeal environments to document them as in (De Waele et al., 2018) and (Fabbri et al., 2017). As proposed in (Serna et al., 2015) the integration of 3D model from TLS and images makes possible the combining of geometric accuracy and texture quality allowing to reach a high level of photorealism. To find ways to visualize and disclose $3 \mathrm{D}$ digital contents is a challenge for the scientific community. Data acquisition and elaboration are fundamental to document UH but communication and dissemination are as well important to spread the knowledge of these hidden places and their historical records. Information and Communication Technology (ICT) are rapidly developing allowing the real-time management of high resolution reality based models giving the possibility to create an alternative immersive reality that replaces the real world (Boas, 2013). The importance of using ICT in order to make culture accessible to a wider audience is demonstrated in (Clini et al., 2017) and in particular IVR digitally could provide an experience of the caves in a non-destructive way of visiting without damaging, dirtying or altering the site (Jiménez Fernández-Palacios et al., 2017).

\section{CASE STUDY}

The case study here presented is Palazzo Campana Caves in Osimo (Figure 2), a complex of underground tunnels and galleries, of uncertain dating, extended below part of the city and served as refuge for the population during the Second World War. The sandstone caves are composed of two sections, one free branch and one rectangular ring. Along walls and vaults of the main galleries, this ring shows several sculpted elements in precarious condition mainly due to human interaction. Because of the material fragility, the main problems are the temperature and humidity variations caused by streams of visitors and the high risk in such a narrow space to hit by accident the walls irreparably damaging the bas-reliefs.

These caves and galleries are configured as underground spaces made up of shadows and symbols. The caves of Palazzo Campana are rich in bas-reliefs and engravings carved into the sandstone, a fragile local stone.

There are many considerations on the origin and the functions of the galleries. The tunnels were certainly used as shelters for the Osimo citizens during the Second World War and were probably also used as water pipes that supplied cisterns, wells and fountains.

The caves are developed according to a ring path and along the two main tunnels some recesses overlook in a specular way (Figure 3). The bas-reliefs of Palazzo Campana are undoubtedly the most fascinating and, at the same time, the most fragile element of the cave complex.

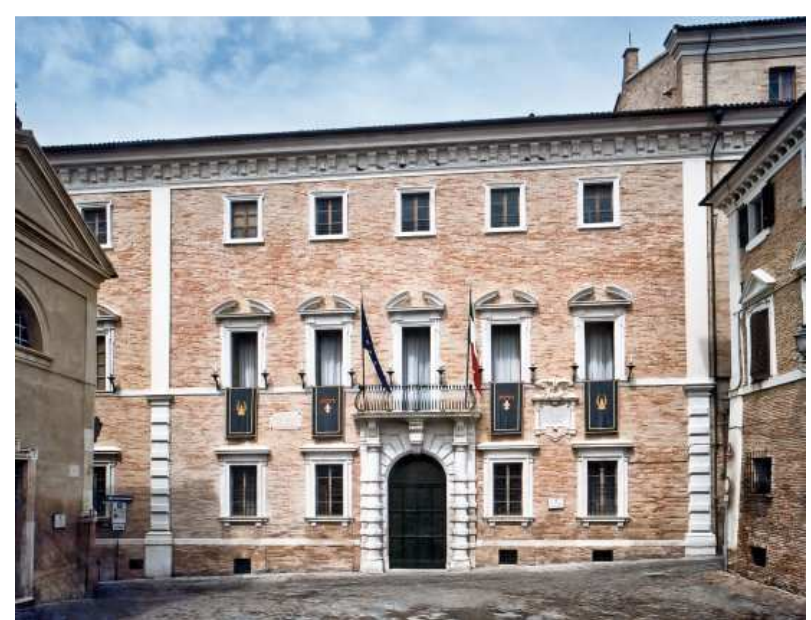

Figure 2: Campana Palace, Osimo. View of the main façade from Dante Alighieri Square.

The caves, dated XVII century, have been the subject of several monographic studies that investigated the bas-reliefs and the origins of the galleries that host them. The iconographic source of the walls and vaults has been identified, from studies such as in (Copparo and Filippetti, 1997), in the "Iconology" of Cesare Ripa.

The interpretations that can be made on the images are difficult both for the bad state of sandstone preservation and because of the construction of some support pillars which resulted in the complete destruction of some portions of decorative apparatus. Along the right side of the first gallery there are bas-reliefs that represent Continents and that personify the Penitence and Intelligence. On the opposite side are described some virtues: Humility, Conversion, Fortitude, Will and Beauty.

At the end of the first gallery there is a square room, partially underground, in which appear two figures inserted in recesses in the shape of shells (Figure 4).

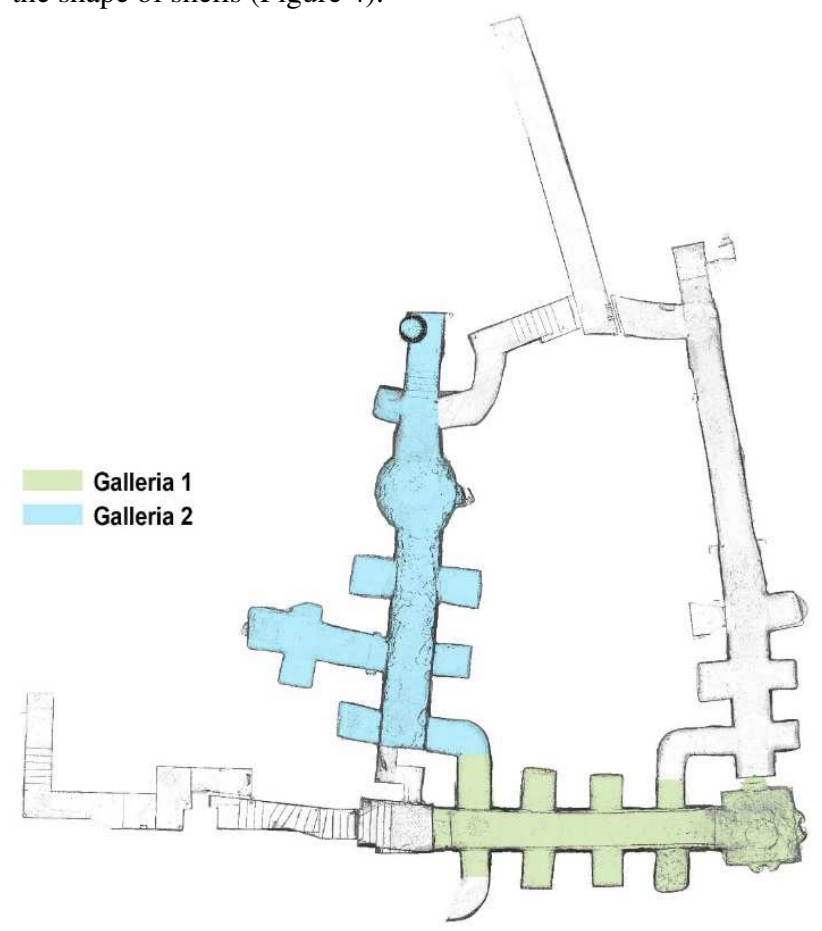

Figure 3: Campana caves plan. The caves are developed according to a ring path, the branch in green is the gallery number 1 and the blue one is number 2 . 


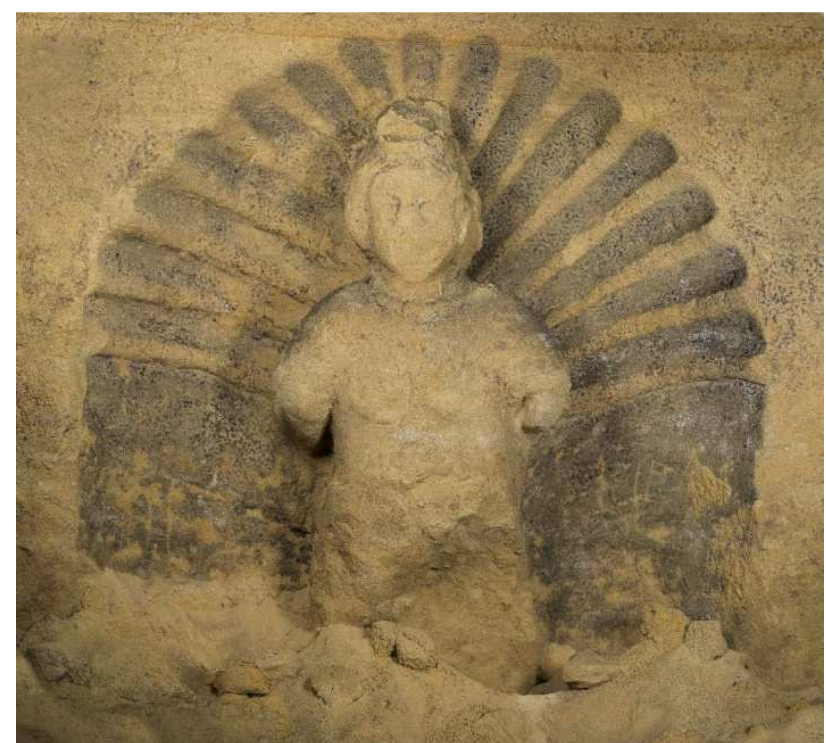

Figure 4: One of the statues contained in the recesses of the square room at the end of the first gallery.

The second gallery is located to the left side of the stairs that come from the upper floors of the building. In addition to the basreliefs on the walls of the recesses this gallery presents rich decorations on the vault that covers the whole environment. This gallery is decorated, like the first, with personifications drawn from the "Iconology" of Ripa: Idolatry, Deceit, Deception. In addition, myths of Greek antiquity are depicted. The second gallery ideally terminates its narrative path with a central plan hall covered with a vault representing some noble arms coats.

Palazzo Campana hypogeum spaces are a priceless treasure and good for the city of Osimo and they should be preserved in the perspective of protection and prevention actions on tangible Cultural Heritage.

\section{DEVELOPED METHODOLOGY}

Nowadays different recording techniques make possible the generation of extremely accurate 3D models. In this study, the integration of TLS and DP is stressed in order to obtain a highresolution photo-realistic 3D model of a narrow-dark space. The workflow is based on data acquisition and $3 \mathrm{D}$ modelling carried out with a particular attention for the subsequent fruition in a VR system.

\subsection{Acquisition and modelling}

In order to survey the complete caves' complex geometry TLS was applied then DP provided the texture to colour it. Four operators carried out the acquisition phases in 2 days, data processing involved two operators for one week.

The instrument used to scan the galleries was a Leica Scanstation P40 laser scanner with a 3D position measurement accuracy of $3 \mathrm{~mm}$ at $50 \mathrm{~m}$. Considering the extension of the scanned area, scanning resolution was set to $3.1 \mathrm{~mm}$ at $10 \mathrm{~m}$. Aware of the difficulty in recognizing natural landmarks to align the 25 underground scans, an extensive use of $\mathrm{b} / \mathrm{w}$ targets was carried out (Figure 5).

All the 39 used targets, positioned on the ground because of the fragility of the sandstone walls, were scanned with an error no worse than $2 \mathrm{~mm}$ according to the manufacturer. Due to the lack of illumination, the laser scanner internal camera was not able to take the spherical photographs of the scanned area to obtain RGB colour information. Therefore, the panoramic images to map the TLS point cloud were assembled from 12 single images taken with a $15 \mathrm{~mm}$ focal length with perspective centre collimated at the scanning centre. Single images were performed using two different lighting conditions each one studied for a specific purpose. The first lighting calibration aimed at obtaining an image with low contrast of lights and shadows, the other with a lighting design able to create an evocative multimedia product for a digital fruition in a Virtual Tour (VT).

A Sony Alpha 9 camera with a $24 \mathrm{~mm}$ focal length and a $6000 \mathrm{x}$ 4000pixel resolution was used to capture the images of the sandstone walls. Most of the time spent in photographic acquisitions was needed for the bas-reliefs due to their convex/concave shape. An average of 60 pictures each were taken. To overcome the low light conditions, photogrammetric acquisitions were performed with the support of a photographic flash kit: two Broncolor Siros $800 \mathrm{~L}$ lamps on a tripod, one equipped with a white soft box and one with a silver reflecting umbrella. Several attempts were carried out to optimize lights positioning and intensity to reach the highest level of detail without creating sharp shadows on the carved wall.

Taking into account the instability of surface condition of the walls, compatibility of optical instruments (laser scanner and flash lamps) with the material of the caves has been previously verified to guarantee that wavelength, power of emitted signals and times of exposure were far from the value of sandstone ablation.

Additionally, to reference the point cloud models, 2 geodetic Ground Control Points were distributed in the open-air scanned area and premeasured via GNSS-RTK (Figure 6).

Then all acquisition data were independently pre-processed. TLS point clouds were aligned using the Leica Software Cyclone. Control points captured via GNSS-RTK were imported into the Geotop software Meridiana for automatic processing. Photos of each single bas-relief were post-produced using Adobe Camera Raw and then imported into Agisoft Software PhotoScan to be aligned (Figure 7). The GSD calculated is enough small to have a good interpretation of surface degradations.

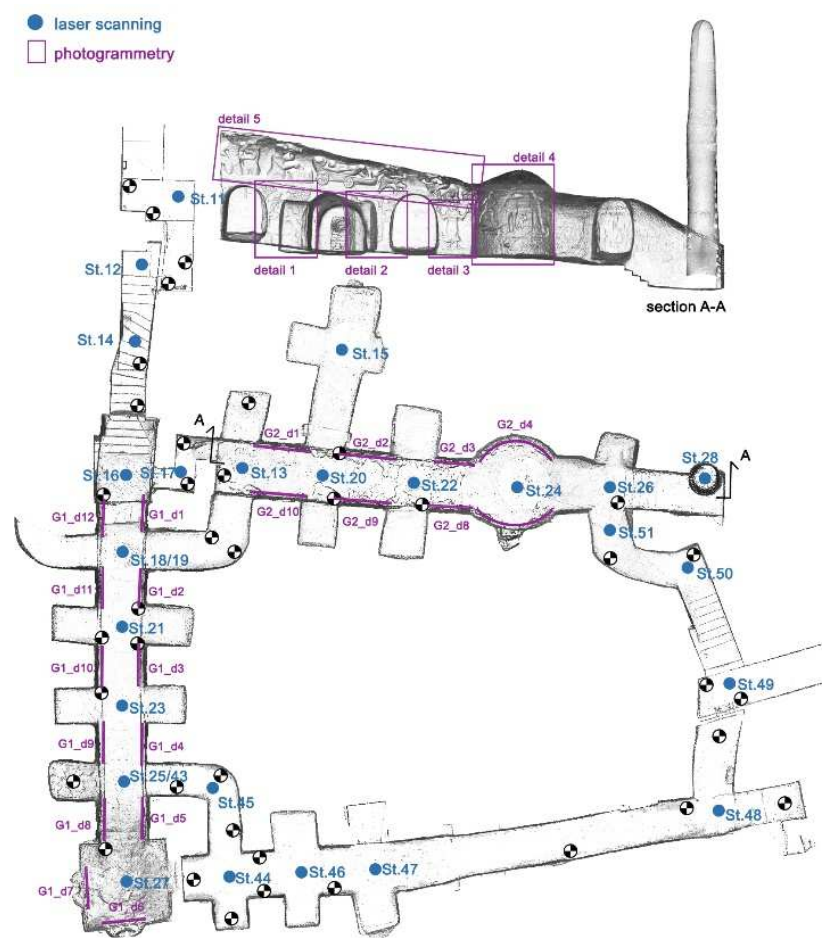

Figure 5: Plan and section of the surveyed galleries with location of TLS stations, targets and photogrammetric acquisitions. 


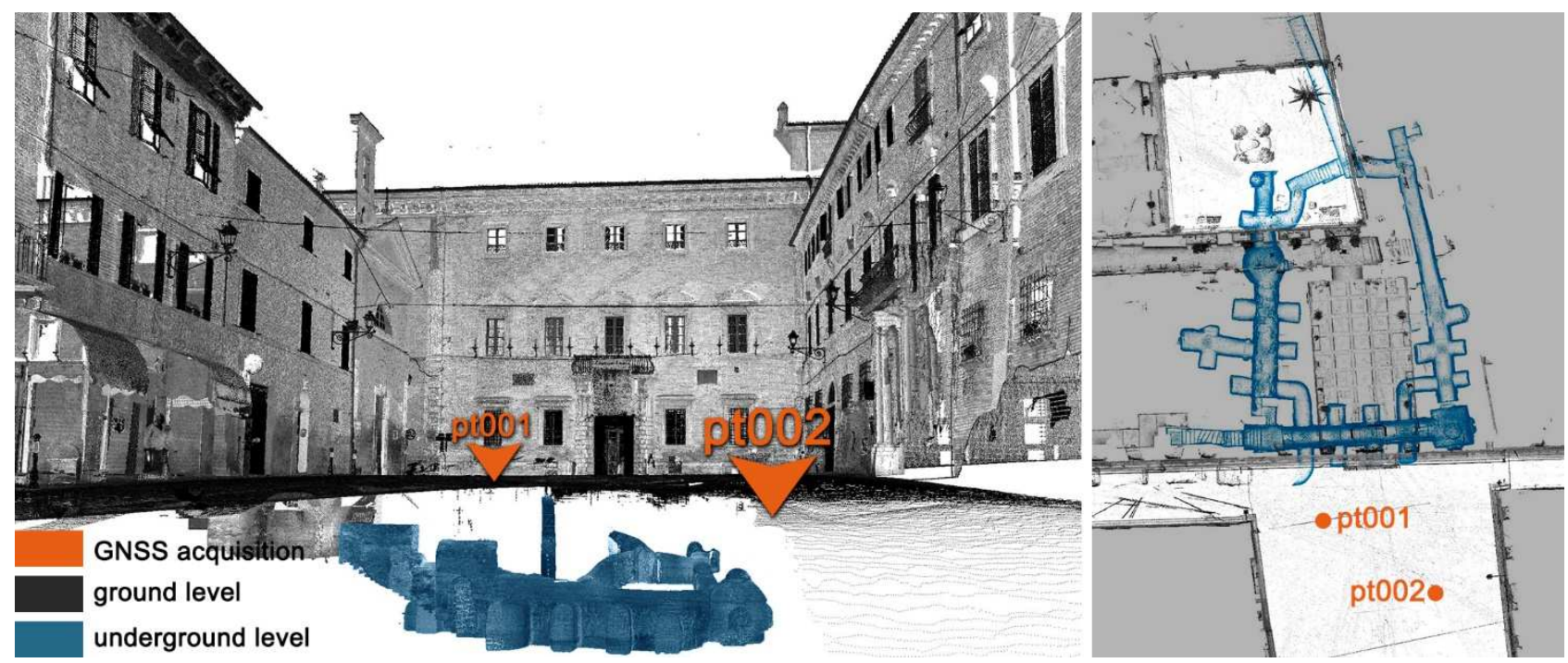

Figure 6: GNSS acquired geodetic Ground Control Points detected in the TLS point cloud.

\section{GALLERY 2_detail 3 (G2_d3)}
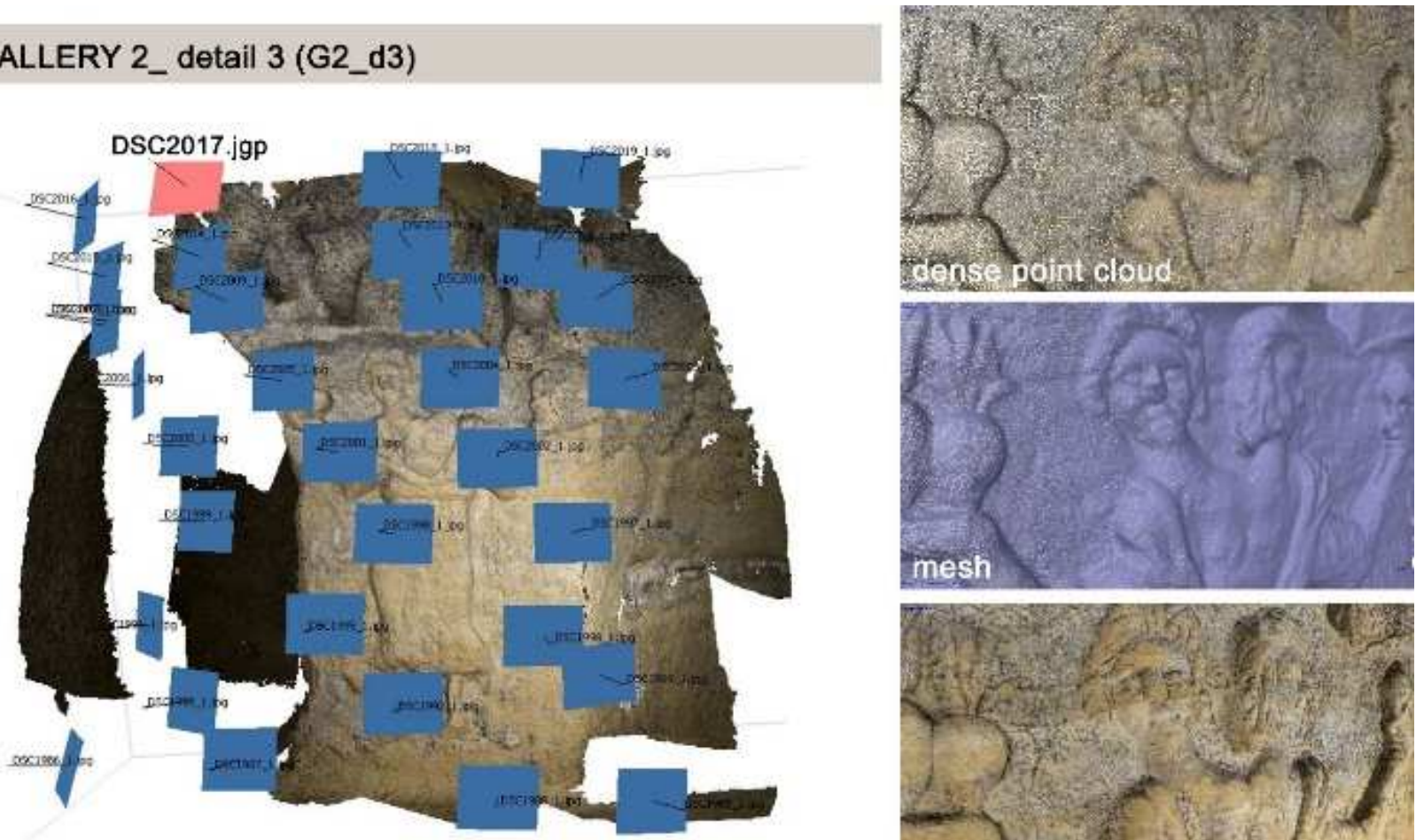

DSC2017.jgp
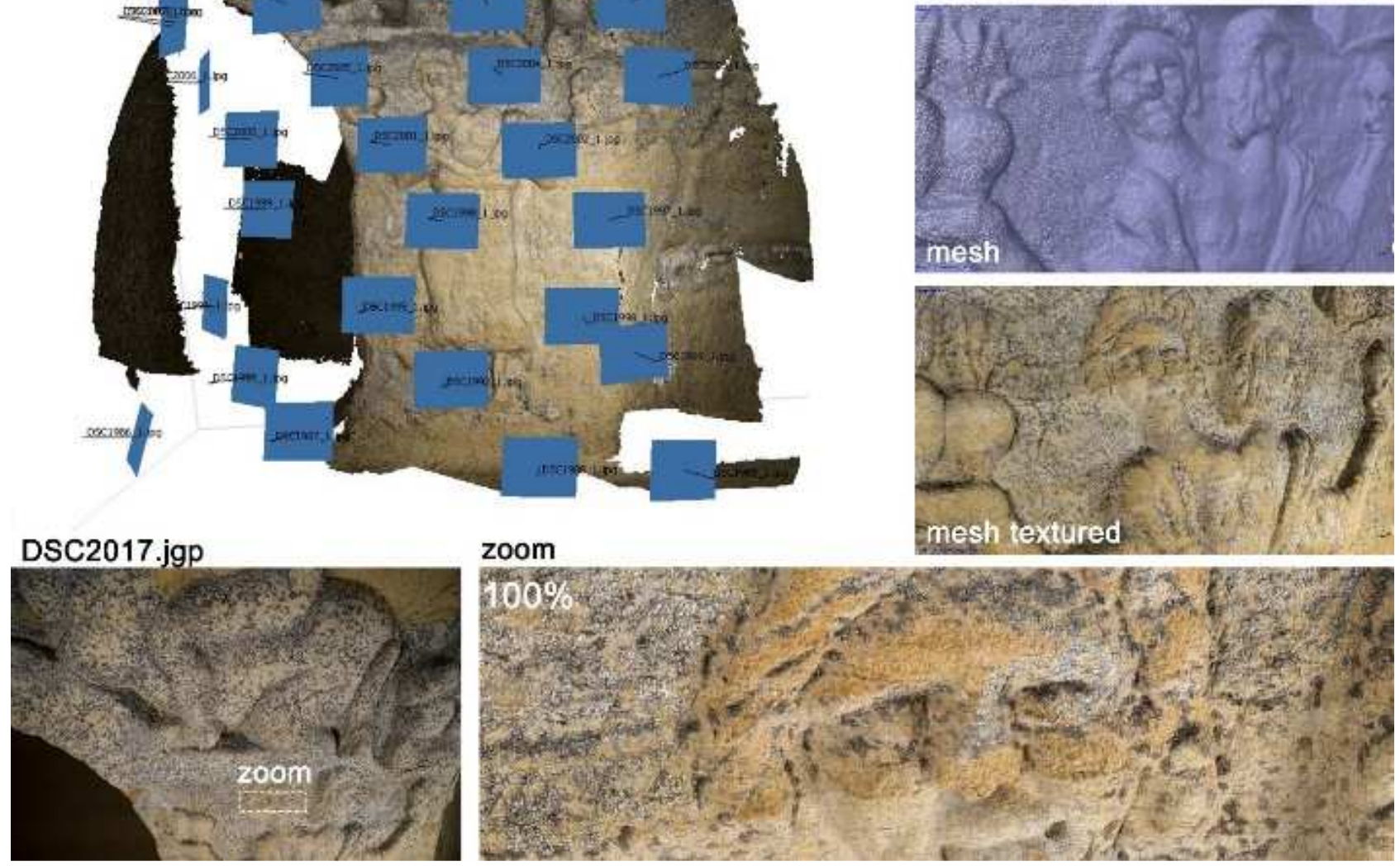

Figure 7: Photogrammetric survey of the detail 3 of second gallery (G2_d3).

The first step of data integration was aimed to set the same reference system for all. With the local coordinates obtained manually positioning the GCPs in the TLS point cloud and their corresponding geodetic coordinate captured from GNSS-RTK, TLS point cloud was georeferenced. Then, a minimum of five feature points was manually detected on each bas-relief set of photos and the corresponding coordinate, extrapolated from the TLS georeferenced point cloud, have been them assigned.

Feature points were used instead of more accurate targets because of the impossibility of positioning them on such a fragile surface. Using the software 3DReshaper, the TLS point cloud was filtered, wrapped into a polygon model and textured using the 
pictures previously aligned (Figure 8). Moreover, the point cloud was projected and sliced in specific directions and position and directly imported in Autodesk AutoCAD to automatically produce $2 \mathrm{D}$ drawings.
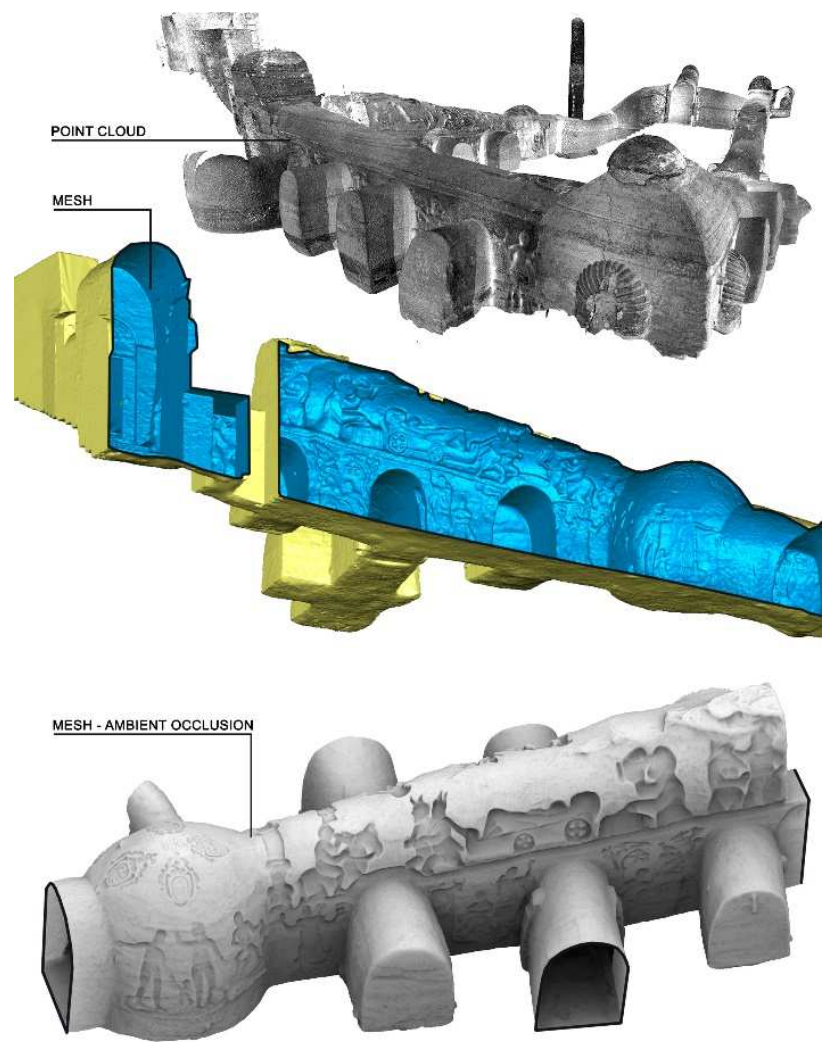

Figure 8: Point cloud acquired by TLS and coloured with intensity value in grey scale (top). Longitudinal section of mesh without texture of Gallery 2 (middle). Mesh with ambient occlusion view of other side of G2 (bottom).

\subsection{VR implementation}

In addition to outputs for experts of conservation, the creation of multimedia products for a wider audience of non-professionals users becomes a way to protect UH from decay. Virtual tour and IVR allow the visitor to walk through the underground galleries and look closer at the decorative bas-reliefs providing an immersive experience without being necessary a potentially dangerous direct interaction with such a fragile environment.

Taking advantage of the Unity game engine's potentialities, two different possibilities were exploited; the first one relies on the use of 2D spherical panoramas, the second one on the elaboration of a 3D model. In the first case, virtual environment is reconstructed in a very expeditious way just taking a series of pictures from the same point of view with a 360-degree horizontal axis rotation and a 180-degree vertical axis rotation. Repeating this acquisition from different points of view, the entire galleries has been covered. Thanks to the use of a wideangle lens, it has been necessary to take a small number of pictures making expeditious the acquisition and elaboration considering that a high level of detail was not required to ensure an adequate perception of the space. In the second case, further elaboration of the 3D model, previously obtained integrating TLS and DP data, allowed to implement it in the IVR application. The model was decimated with "curvature priority" in order to preserve more details where the curvature was higher. Once the geometry was simplified reducing the number of the polygons, the UV coordinates has been generated for each vertex in the mesh with the unwrapping operation. The last step was the projection of the geometric and visual characteristics of the highpoly model on the low-poly one that is essential to make the user believe that he is looking at a detailed model.

In both cases, the immersive fruition was possible thanks to a PC with an HTC Vive system and a monitor. Composed by a headmounted display with a camera near the bottom rim, two wireless motion tracked handheld controllers and two "lighthouse" basestations for "room scale", HTC Vive system allows to replicate the natural movements of the user's body in the virtual reality. The headset thanks to features like a resolution of $1080 \times 1200$ pixels per eyes, a field of view of 110 degrees and a SteamVR Tracking to find the location of each sensor, a Gsensor, a gyroscope and proximity sensor, is a very powerful and valuable device for VR applications. The use of two combined basestations, essentially two-multi axis laser emitter, guarantees 360 degrees coverage while the two controllers allow the interaction with things inside the virtual space.

So the possibilities offered by this technology has been exploited to enrich user experience structuring the virtual space as a learning path that shows to the visitor the figures carved in the stone with a specific storytelling. Thanks to buttons combination of the HTC Vive controllers, it is possible to recall a map of the galleries that shows where the visitor is. In the virtual space were also displaced different kinds of hotspot. Position hotspots lead to a different point in the space whereas info hotspots let to visualize information about a specific element (Figure 9).

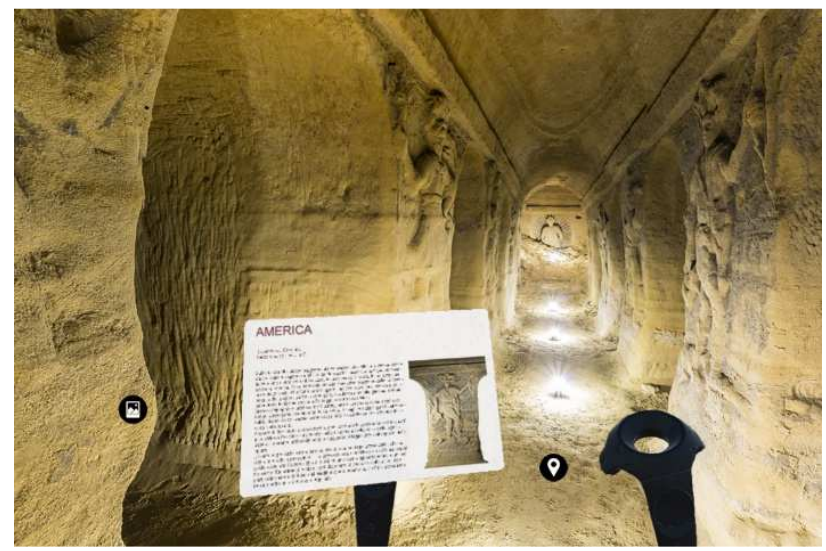

Figure 9: Immersive Virtual Reality, visualization of info about the selected bas-relief inside a spherical panorama

The main difference using a 3D model instead of a 2D panorama image is in the user point of view that can change following user movements instead of being fixed on the point of view determined by camera position during the acquisition phase. The SteamVR Tracking Basestations sweep the room with multiple sync pulses and laser lines, reaching out to about 5 meters. By keeping careful track of the timings between pulses and sweeps, the SteamVR Tracking system uses simple trigonometry to find the location of each sensor to within a fraction of a millimetre. By combining multiple sensors, 2 basestations, as well as adding a high speed IMU (inertial measurement unit), SteamVR also calculates the tracked object's orientation, velocity, and angular velocity, all at an update rate of $1000 \mathrm{~Hz}$. So loading a 3D space reconstruction instead of a $2 \mathrm{D}$ panorama, the HTC Vive system is able to let the user move inside the virtual space as in the real one, getting closer to a wall or to any other point of interest. To overcome the space limits determined by the field of view of the basestations, about $5 \times 5$ meters, it is possible to use the controllers as laser pointers. Any visible point can be reached just pointing it. The coordinate system of the virtual space is then recalculated around this point as well as the new space limits. 


\section{CONCLUSIONS}

This work stresses the importance of an integrated survey to overcome difficulties in documentation of UH usually characterized by dark and narrow spaces. Thanks to the use of different methods and tools, the study site was accurately and completely documented and displayed.

Reflectance values got from TLS acquisitions compared with those of high-resolution photographic acquisitions can provide detailed information about sandstone conservative state. In this regard it appeared that the majority of the bas-reliefs of the two main galleries are in bad condition of conservation.

The results obtained from the integration of the methods show that they both are valid for a detailed analysis of this type of sandstone and that they give good outputs not only in geometric, but also in visual aspects, thanks to accurate project of light conditions. In fact, in addition to outputs for experts of conservation, this work presents the creation of multimedia products for a wider audience of non-professionals users that becomes a way of protecting the UH from decay.

Thanks to the performed case study, the paper is able to show a method to obtain an interactive visualization and access to 3D models using VR techniques. The achieved results, allow visitors to view digital underground environments at $360^{\circ}$ and walk through the galleries observing the decorative bas-reliefs without it being necessary to directly come into contact with the real one. The Campana Foundation will host a multimedia permanent exhibition with Virtual tour and IVR.

\section{ACKNOWLEDGEMENTS}

We would like to thank the Campana Institute of Osimo for having commissioned us the work and allowed to access and work on such a precious heritage. In particular, we are grateful to Giulia Lavagnoli for all organisational aspects. Furthermore, we thank Prof. Marco D'Orazio who dealt with the environmental monitoring of the caves and supported us in evaluating the environmental safety of the equipment and methodology to use.

\section{REFERENCES}

Boas, Y., 2013. Overview of Virtual Reality Technologies. Mms.Ecs.Soton.Ac.Uk.

Cardaci, A., Versaci, A., Fauzia, L.R., 2016. Between Archaeology and Landscape. Analysis, Con- servation and Valorisation of Early Christian Hypogean Com plexes of the South-Eastern Sicily, in: Landscape \& Archaeology En-Route International Seminar in Flaminia, Fano, Fossombrone, Cagli, Italy, 23-25 June 2016. I QUADERNI DI CAREGGI, pp. 40-48.

Clini, P., Nespeca, R., Ruggeri, L., 2017. Virtual in real. Interactive solutions for learning and communication in the national archaeological museum of Marche, in: International Archives of the Photogrammetry, Remote Sensing and Spatial Information Sciences - ISPRS Archives. pp. 647-654. doi:10.5194/isprs-Archives-XLII-5-W1-647-2017

Copparo, F., Filippetti, F., 1997. I tarocchi di pietra del Palazza Campana di Osimo.

De Waele, J., Fabbri, S., Santagata, T., Chiarini, V., Columbu, A., Pisani, L., 2018. Geomorphological and speleogenetical observations using terrestrial laser scanning and 3D photogrammetry in a gypsum cave (Emilia Romagna, N. Italy). Geomorphology 319, 47-61. doi:10.1016/j.geomorph.2018.07.012
Fabbri, S., Sauro, F., Santagata, T., Rossi, G., De Waele, J., 2017. High-resolution 3-D mapping using terrestrial laser scanning as a tool for geomorphological and speleogenetical studies in caves: An example from the Lessini mountains (North Italy). Geomorphology 280, 16-29. doi:10.1016/j.geomorph.2016.12.001

Jiménez Fernández-Palacios, B., Morabito, D., Remondino, F., 2017. Access to complex reality-based 3D models using virtual reality solutions. J. Cult. Herit. 23, 40-48. doi:10.1016/j.culher.2016.09.003

Lerma, J.L., Navarro, S., Cabrelles, M., Villaverde, V., 2010. Terrestrial laser scanning and close range photogrammetry for 3D archaeological documentation: the Upper Palaeolithic Cave of Parpalló as a case study. J. Archaeol. Sci. 37, 499-507. doi:10.1016/j.jas.2009.10.011

Liang, H., Li, W., Lai, S., Zhu, L., Jiang, W., Zhang, Q., 2018. The integration of terrestrial laser scanning and terrestrial and unmanned aerial vehicle digital photogrammetry for the documentation of Chinese classical gardens - A case study of Huanxiu Shanzhuang, Suzhou, China. J. Cult. Herit. doi:10.1016/j.culher.2018.03.004

Mandelli, A., Fassi, F., Perfetti, L., Polari, C., 2017. Testing different survey techniques to model architectonic narrow spaces, in: International Archives of the Photogrammetry, Remote Sensing and Spatial Information Sciences - ISPRS Archives. doi:10.5194/isprs-archives-XLII-2-W5-505-2017

Murtiyoso, A., Grussenmeyer, P., Guillemin, S., Prilaux, G., 2017. CENTENARY of the BATTLE of VIMY (FRANCE, 1917): PRESERVING the MEMORY of the GREAT WAR THROUGH 3D RECORDING of the MAISON BLANCHE SOUTERRAINE, in: ISPRS Annals of the Photogrammetry, Remote Sensing and Spatial Information Sciences. pp. 171-177. doi:10.5194/isprs-annals-IV-2-W2-171-2017

Rodríguez-Gonzálvez, P., Nocerino, E., Menna, F., Minto, S., Remondino, F., 2015. 3D Surveying and modeling of underground passages in wwi fortifications. Int. Arch. Photogramm. Remote Sens. Spat. Inf. Sci. - ISPRS Arch. 40, 1724. doi:10.5194/isprsarchives-XL-5-W4-17-2015

Serna, C.G., Pillay, R., Trémeau, A., 2015. Data fusion of objects using techniques such as laser scanning, structured light and photogrammetry for cultural heritage applications, in: Lecture Notes in Computer Science (Including Subseries Lecture Notes in Artificial Intelligence and Lecture Notes in Bioinformatics). pp. 208-224. doi:10.1007/978-3-319-15979-9_20 